\title{
Process Quality of Antenatal Care Among Clients of Antenatal Care Service Users and Service Providers in Public Hospitals of Woliata Zone, Southern Ethiopia
} \author{
${ }^{1}$ Assistant Professor. BSc (Environmental Health), MPH (Health Services Management), Woliata Sodo University, Ethiopia \\ ${ }^{2}$ Associate Professor (Epi \& Biostats), SPHPSS, University College Dublin, Ireland \\ ${ }^{3}$ Professor of Obstetrics, UCD and National Maternity Hospital, Dublin \\ ${ }^{4}$ Assistant Professor of Public Health, SPHPSS, UCD \\ ${ }^{5}$ School of Medicine, College of Health Sciences and Medicine, Woliata Sodo University, Wolaita Sodo, Ethiopia
}

Niguse Mekonnen ${ }^{1 *}$, Takele Tadesse ${ }^{1}$, Mary Codd $^{2}$, Fionuala McAuliffe ${ }^{3}$, Carla Perrotta ${ }^{4}$ and Abenet Desalegn ${ }^{5}$

Submission: December 18, 2020; Published: January 05, 2021

*Corresponding author: Niguse Mekonnen, Assistant Professor. BSc (Environmental Health), MPH (Health Services Management), Woliata Sodo University, Ethiopia

\begin{abstract}
Background: Many women are dying due to factors related to pregnancy and childbirth, especially in developing countries including Ethiopia, where maternal mortality ratio is one of the highest in the world. In Ethiopia, most women have had antenatal care visit, however the goal, reduction in maternal mortality, is yet not in line with the 2030 Sustainable Development Goal particularly in rural areas, where the process quality has gap.

Methods and Objectives: Facility-based cross-sectional study was to determine sum score of process quality of Antenatal care services among mothers who attended antenatal care service during the study period in Woliata Zone, Southern Ethiopia. Data collection took place using smart phones running Google's Android operating system from 704 participants via observation. The phones were equipped with Open Data Kit (ODK) software. Logistic regression was performed using SPSS version 24.0

Result: A total of 704 pregnant women were included in the analysis. Only $52.3 \%$ of antenatal care attendants met Process quality of the service in antenatal clinic while discussing with the service provider. In binary logistic regression; advise the client to use skilled health worker for delivery AOR= $21.0(95 \% \mathrm{CI}: 6.3,69.6)$, discussed heavy vaginal bleeding during or after birth $\mathrm{AOR}=1.6(95 \% \mathrm{CI}: 1.0,2.5)$, take client's blood pressure AOR,2.1(95\%CI:1.1, 4.2), asked the client where she will deliver AOR $=2.6(95 \% \mathrm{CI}: 1.7,4.2)$, advise the client to prepare for delivery AOR, 3.1 (95\% CI : 2.0,4.9), provide counselling related to HIV AOR=1.8(95\%CI:1.0,3.0) and examine conjunctiva or palms for anaemia $\mathrm{AOR}=1.8(95 \% \mathrm{CI}: 1.0,3.1)$ were statistically significant predictors of the process quality of antenatal care service in the study period in Woliata Zone, Southern Ethiopia.

Conclusion: Sum score of Process quality of Care among antenatal care service users was low compared to national standard. Informing women that getting standard process quality service is their right, and encouragement of mothers regarding the need for Process quality of the services is of crucial. Providers must be in line with principles of screening and counselling.
\end{abstract}

Keywords: Process Quality; Antenatal Care; Woliata zone; Public hospital; Southern Ethiopia

\section{Introduction}

Developing regions account for approximately 99\% (302,000) of the global maternal deaths which is roughly 20 times higher than that of developed regions, whereas sub-Saharan Africa (SSA) alone accounting for roughly $66 \%$ [1-6]. Maternal and child mortality have declined over the past 20 years in Ethiopia. However, 2015 estimates show that mortality remains high in the months before 
and after childbirth, with 420 mothers dying per 100,000 live births, 41 infants dying per 1000 live births, 28 neonates dying per 1000 live births and neonatal deaths accounting for $47 \%$ of all under-five mortality $[7,8]$ In line with Sustainable Development Goals, by 2020 Ethiopia aims to reduce the maternal mortality ratio to 199 per 100,000 live births, the infant mortality rate to 20 per 1000 live births and the neonatal mortality rate to 10 per 1000 live births, [9].

This requires more than three times the $2.3 \%$ annual rate of reduction observed globally between 1990 and 2015 [7,10]. In developing countries, however, interest in improving process quality of health care has been surprisingly low until recently. This is so, despite overwhelming published and anecdotal evidence of low quality of care in these countries [11,12]. In Ethiopia, health services are limited and of poor quality $[11,13]$ and the country has extremely poor health status relative to other low-income countries. Quality of health care is the application of medical science and technology in a way that maximizes its benefits to health without correspondingly increasing its risks. The degree of quality is, therefore, the extent to which the care provided is expected to achieve the most favourable balance of benefits and risks [14].

Process Quality of care denotes, what is done in giving and receiving care. It includes the patient's activities in seeking care and carrying it out as well as the practitioner's activities in making a diagnosis and recommending or implementing treatment [15] Interactions between health care providers and their patients are widely recognized to play an important role in determining the uptake of health services [16,17], and satisfaction with health services has been documented [16,18,19] Patient-provider interactions have been conceptualized with a range of theoretical models, evolving over time from traditional paternalistic or biomedical models of care, towards a more 'patient-centered' approach. Balint first introduced the theory of patient-centered medicine in the 1950s $[16,20]$.

The World Health Organization (WHO) envisions a world where every pregnant woman and new-born receive quality care throughout the pregnancy, childbirth, and the postnatal period. If the quality of ANC is poor and women's experience of it is negative, the evidence shows that women will not attend ANC, irrespective of the number of recommended contacts in the ANC model $[6,21]$. Thus, the overarching aim of the ANC model is to provide pregnant women with respectful, individualized, personcentred care at every contact, with the implementation of effective clinical practices (interventions and tests), and provision of relevant and timely information, and psychosocial and emotional support, by practitioners with good clinical and interpersonal skills within a well-functioning health system. Each visit should include care that is appropriate to the woman's overall condition and stage of pregnancy and help her prepare for birth and care for the new-born. If problems or potential problems that will affect the pregnancy and new-born are detected the frequency and scopes of visits are increased. Therefore, the major goal of ANC is to help women maintain normal pregnancies through identification of pre-existing health conditions, early detection of complications arising during pregnancy, health promotion and disease prevention and birth preparedness and complication readiness planning [21,22].

The goal of the new ANC model is to improve the quality of ANC and to improve maternal, foetal and new-born outcomes related to ANC $[21,23]$. Thus, to reduce birth complication and its consequences on the health of pregnant mothers and children, WHO recommended ANC services should be offered from primary health with the required quality of each intervention to reduce maternal and neonatal mortality and thereby attain Sustainable Development Goal 2030.Goal 3 at sub-articles 3.1 and 3.2. Which set a target to reduce maternal mortality ratio to less than70/100,000 live birth and reducing neonatal mortality to at least as low as 12 per 1,000 live births by 2030 [24]. Therefore, this study focused on the process quality of ANC, this would have the potential to improve the quality of ANC from process perspectives then would help in reducing maternal and neonatal mortality in the study area and Ethiopia at large thereby it contributes to addressing the SDG2030.

\section{Methods and Materials}

Public hospitals based cross sectional study was conducted to determine the status of process quality antenatal care services and its associated factors among 704 services users and service providers in public hospitals of Wolaita Zone, Southern Ethiopia. Wolaita Zone, which is 380 kilometres to the South of Addis Ababa, the capital city of Ethiopia. Wolaita Sodo is the main town of Wolaita Zone. Women of reproductive age were estimated to be $473,075(23.3 \%)$ and out of which pregnant women were estimated to be 65,812 [25]. All pregnant women attending Public (three primary and one tertiary) hospitals were used as source population for the study, and the study subjects were sampled antenatal care attending women from these setting. A total of $4 / 58 \%$ / public health hospitals were selected from three districts and one town administration. All pregnant women who reside in the study area for six months and above and attend antenatal care within the data collection period and those with gestational age less or equal to 16 weeks, and more than 16 weeks of gestation were included. pregnant women who are seriously sick and did not allow the observation of the provision process of the services.

The sample size for the study is calculated using a single population proportion formula by taking $32.2 \%$ proportion of pregnant women who were satisfied of service access and provision in health facilities of West Amhara region [26]. considering 5\% margin of error (d) and confidence level of $95 \%$ ( $\mathrm{z} \alpha / 2=1.96$ ). Based on the above information a sample size is 335 . Adding $5 \%$ non- response rate, and a design effect of 2 
[27] the final sample size is $\mathbf{7 0 4}$ which was found to be the largest sample size for process quality of Antenatal care services.

$\mathrm{n}=(\mathrm{Z} \alpha / 2)^{2} \mathrm{p}(1-\mathrm{p}) * \mathrm{D}=(1.96)^{2 . * 0.322 *} \cdot 0.678 * 2 * 3.8416$

Where:

$d^{2}(0.05)^{2}$

$\mathrm{ni}=$ initial Sample size, $\mathrm{Z} \alpha / 2$ = Confidence level at $95 \%=1.96$, $\mathrm{P}=$ Proportion of pregnant women who were satisfied of service access and provision in health facilities of West Amhara region during ANC visit32.2\% (26)d = margin of error of $5 \%$,

\section{$\mathrm{D}=$ design effect}

On the information obtained from the study area primary and tertiary hospitals, those women who attended ANC at four hospitals every day were addressed. Then study subjects were taken randomly from each hospital (Figure 1).

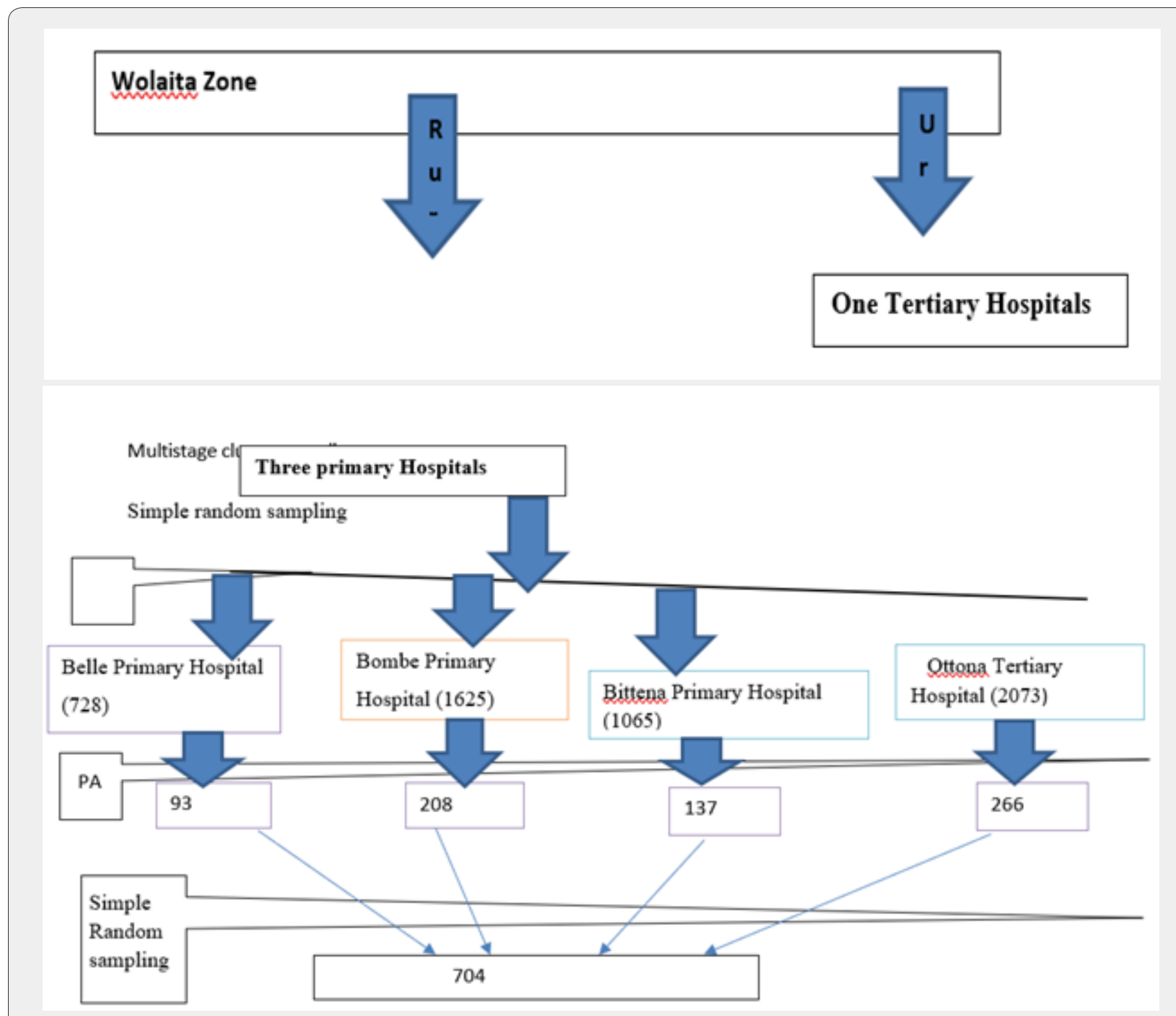

Figure 1: Schematic representation of sampling procedure on Process quality of antenatal care service in primary and tertiary public Hospitals of Wolaita Zone from Nov-February 2019.

Data collection tool is adapted from JHIOIGO, which stands for Johns Hopkins Program for International Education in Gynaecology and Obstetrics, International Federation of Gynaecology and Obstetrics, \& Leadership in Obstetrics and Gynaecology for Impact and Change (FIGO LOGIC), Ethiopian Demographic Health Survey (EDHS), WHO safe mother hood assessment tool and different literatures of similar studies and modified according to the local context \& objectives of this study by the principal investigator. Initially the questionnaire was prepared in English then it was translated to local language Amharic and back to English by two persons who have good ability of both languages to keep its consistency. 
Direct observation checklists which (includes provider information, information about observation, ANC consultation, client history, aspect of previous pregnancy, danger sign of current pregnancy, physical examination, routine tests, HIV counselling and testing, 'maintaining a healthy pregnancy, iron prophylaxis, tetanus toxin injection, deworming, malaria, preparation for delivery, new born, and post-partum recommendation). Data collection Procedure took place using smart phones running Google's Android operating system. The phones were equipped with Open Data Kit (ODK) software. Six data collectors who were composed of two epidemiologist, two midwives, one B.Sc. female nurses, one B.Sc. public health officer and, who have had in service training on ANC \& have experience on data collection were selected for data collection and four supervisors such as one MSc. Midwifery, one obstetric and gynaecologist specialist, one MSc. in integrated obstetrics and gynaecology surgeon, one epidemiologist and supervisors from other health institutions, were trained for five days on data collection process and the Open Data collection Kit (ODK) application software. At the time of the actual data collection, the data collectors arrived early in the morning and gave clients' small card with recorded time of arrival. All pregnant women who were registered for antenatal care were observed until the required sample size was obtained. Data on the types of services ANC attendees received was collected through direct observation.

\section{Dependent Variables}

Sum score of Process Quality of Antenatal Care services. The independent variables were Socio-demographic variables service provider (provider information sex of provider, age of provider, year of experience of provider), (client history, aspects of prior pregnancy, danger sign of current pregnancy, physical examination, routine tests, HIV counselling and testing, maintaining healthy pregnancy, iron prophylaxis, tetanus toxoid injection, deworming, malaria and preparation for delivery interaction with the service receivers or clients).

\section{Operational Definition}

Process quality of care: denotes, what is done in giving and receiving care. It includes the patient's activities in seeking care and carrying it out as well as the practitioner's activities in making a diagnosis and recommending or implementing treatment [15].

Process standards Quality: describe the tasks or steps that must be carried out until the activity is completed (effectiveness, safety, patient centeredness, efficiency, equity, timeliness of care) [28].

Sum score process quality of care: In this study a median of the sum score of the provider information, information about observation, ANC consultation, client history, aspect of previous pregnancy, danger sign of current pregnancy, physical examination, routine tests, HIV counselling and testing, 'maintaining a healthy pregnancy, iron prophylaxis, tetanus toxin injection, deworming, malaria, preparation for delivery, new born, and post-partum recommendation were used to measure the process quality of antenatal care service. The median value was used since it is said that it is preferable to measure if there is some sort of skewedness in the distribution of the data. here ,the median was 49.0, the mean was 50.8421 with $\mathrm{SD} \pm 12.36$ thus, the process quality of ANC service was categorized by the median, above median or equal to the median score was said to be met the standard, and below the median said to be unmet the standard.

Primary hospital: Shall mean a health facility at primary level of healthcare which provides promotive, preventive, curative and rehabilitative services with a minimum capacity of 35 beds and provides at least 24-hour emergency services, general medical services, treatment of basic acute and chronic medical problems, basic emergency surgical intervention and Comprehensive Emergency Obstetric Care (CEOC) including laboratory, imaging and pharmacy services and other related services stated under this standard [29].

Primary hospital: shall have separate maternal and child health care $(\mathrm{MCH})$ service unit with the following minimum requirements: two room for ANC/ PMTCT, PNC services, One room for Immunization service, with Cold chain room/corner, One room for Growth monitoring services, Sick baby clinic/ under five clinic services: two rooms for Family planning services, waiting area with shade, and The MCH rooms shall respect the privacy and dignity of clients [29].

The MCH service shall have the following equipment: Examination coaches, Gynaecologic coaches, Stethoscope, Sphygmomanometer, thermometer, weighing scale, adult, Specula of different size, infant meter and height scale, Otoscope, Fetoscope, Stand lamp, Refrigerator and Cold chain boxes [29].

Data processing and analysis: Data collection took place using smart phones running Google's Android operating system. The phones were equipped with Open Data Kit (ODK) software; then exported to excel then to SPSS version 24 for analysis. Data was cleaned and coded. Descriptive statistics such as frequencies, mean, median, SD, percentage were carried out to see tables and graphs as appropriate. Binary, multivariable logistic regression analysis was carried out to identify factors associated with Process quality of Antenatal Car services (ANC) while delivering of ANC service controlling the effect of confounding variables. A pvalue $<0.05$ was considered as statistically significant. A crud and adjusted odds ratios were used to see the strength of association with $95 \%$ CI. Variables with p value $<0.25$ in the bivariate analysis was candidates for analysis. Finally, the model was constructed.

Data quality management: Training was given for both data collectors and supervisor by the principal investigator for five days on the overall organization of data collection, principles, ethics and in operating ODK app in which the data collection tool was developed. The training covers the objectives of the study 'method of data collection and theoretical and practical section of ODK app. Pre-testing of the questionnaire was carried out on $5 \%$ 
(35) pregnant women at adjacent health facilities which is found in the adjacent zones of the study area in order to evaluates the appearance of the questionnaire in terms of feasibility, readability, consistency of styles, formatting and the clarity of the language used. Wording logic behind and consequently edited and used the most applicable questions. During actual data collection at the end of each day, the questionnaire was checked for completeness, accuracy and consistency by the supervisors and investigator and corrective action was undertaken with all the data collectors and the supervisors. The internal consistency of the data was checked, and Cronbach alpha was 0.717

\section{Ethical Consideration}

Data was collected after obtaining full ethical approval from the School of public health, sport and Physiotherapy Science, Dublin, Ireland (HRECs), and Wolaita Sodo University, institutional review Board (IRB). The respondents have the right to refuse participation or terminate their involvement at any point during the observation. They were informed that there was not any penalty for withdrawal. The information gathered via direct observation from each respondent was kept confidential. All data collected was anonymized. Access rights to data was strictly confined only to those researchers requiring access in order to further ensure the anonymity of participants. Once access rights had been established, data storage arrangements reflect the sensitivity of the data. Physical notes and surveys data were stored securely and electronic files containing data was encrypted. Complete anonymization of data was taken place.

\section{Result}

The overall sum score of process quality of antenatal care service met in this study was 368 (52.3\%) when observed during the study period. $438(62.2 \%)$ of the study participants have had the process with female health care providers whereas $266(37.8 \%)$ interacted with male health care provider. The mean $( \pm$ SD) age was $30.22( \pm 3.33)$ years. Large proportion of participants $163(23.3 \%$, were 33 years old whereas the smallest proportion2 (0.3\%) lies between 34 and 36 years old (Figure 2). As it could be observed,382(54.3\%) most study participants had had ANC process with midwifery professionals whereas the least with enrolled nurse that is less than one percent (Figures 3-5) (Tables 1-5).

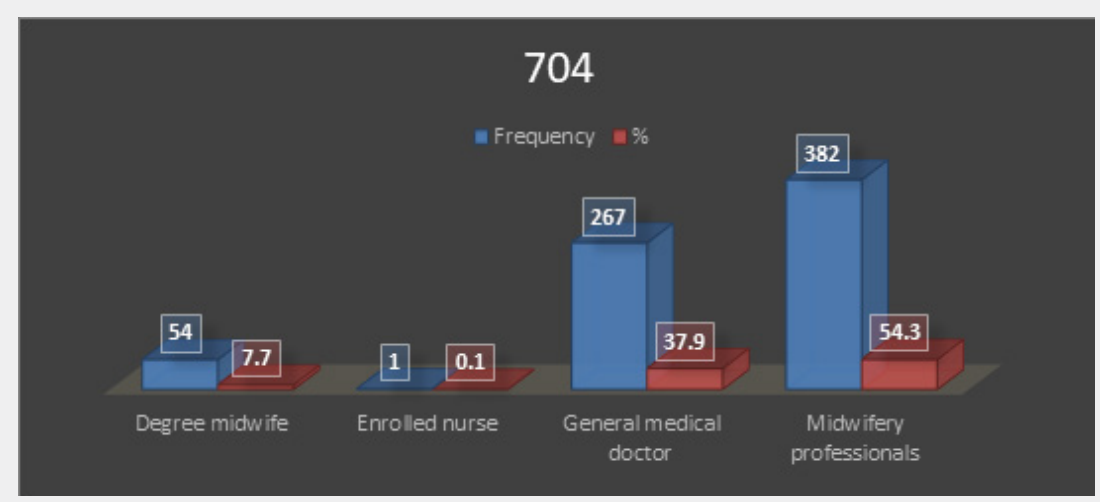

Figure 2: Antenatal Care service users who have been Interaction process with varies health care service providers at Public Hospitals of Woliata Zone, Southern Ethiopia, Nov-Feb 2019.

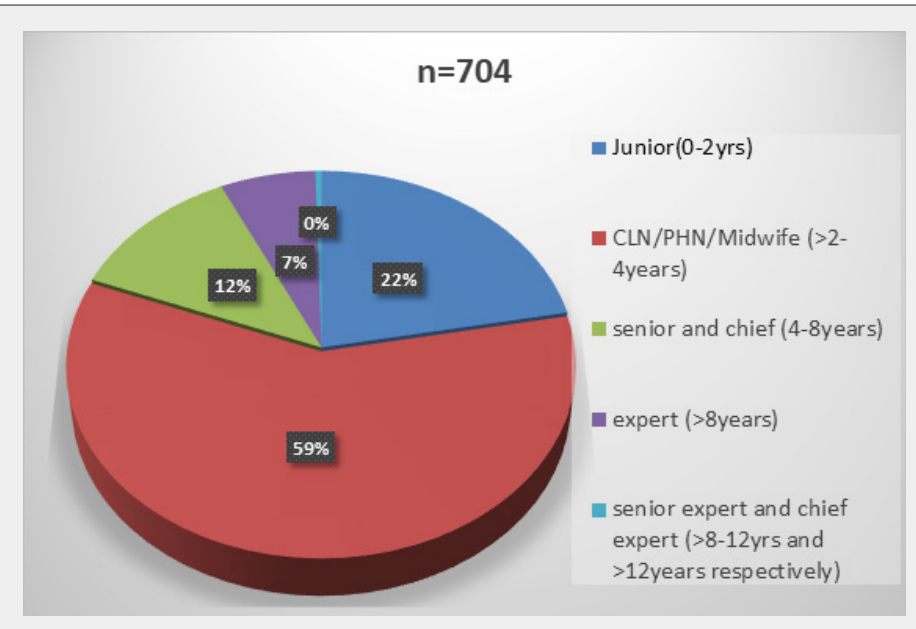

Figure 3: percentage distribution of respondents who have been interacted by health care providers who differ in their expertise level in woliata Zone, Southern Ethiopia Nov-Feb/2019. 


\section{Journal of Gynecology and Women's Health}

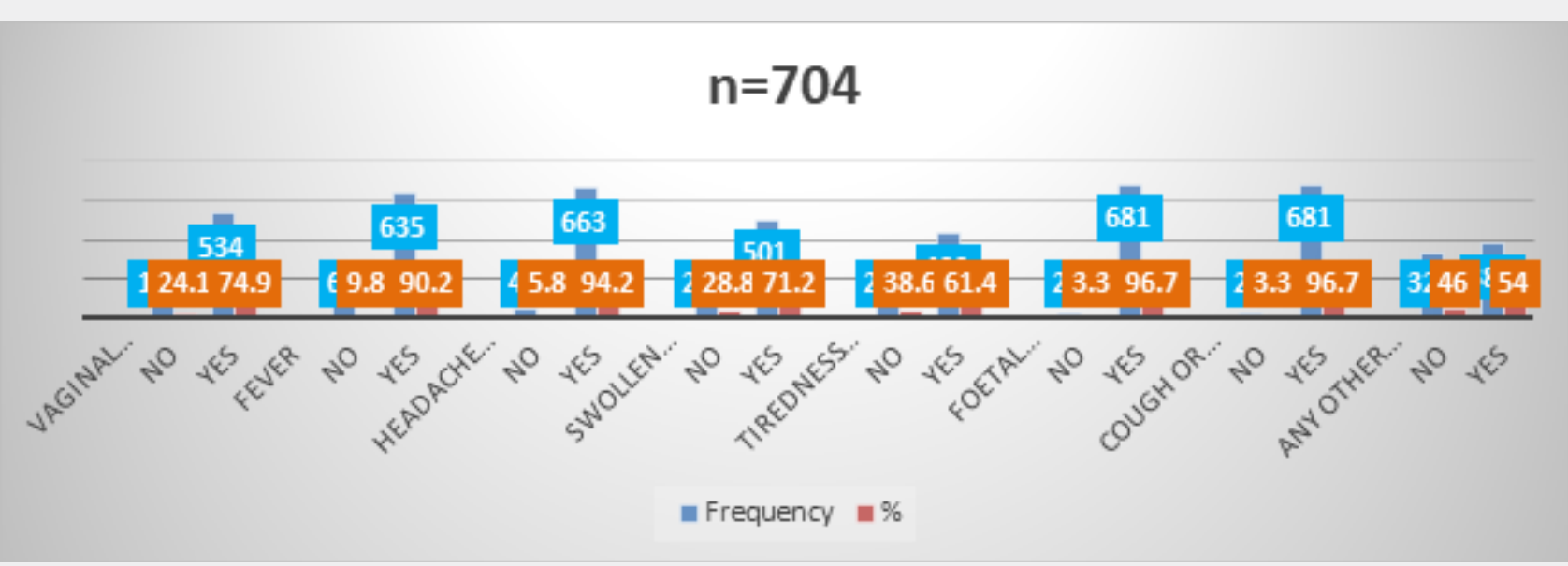

Figure 4: Service provider-client interaction process on counselling danger sign of current pregnancy among Antenatal care service user at Public hospitals of Woliata Zone, Southern Ethiopia Nov-Feb 2019.

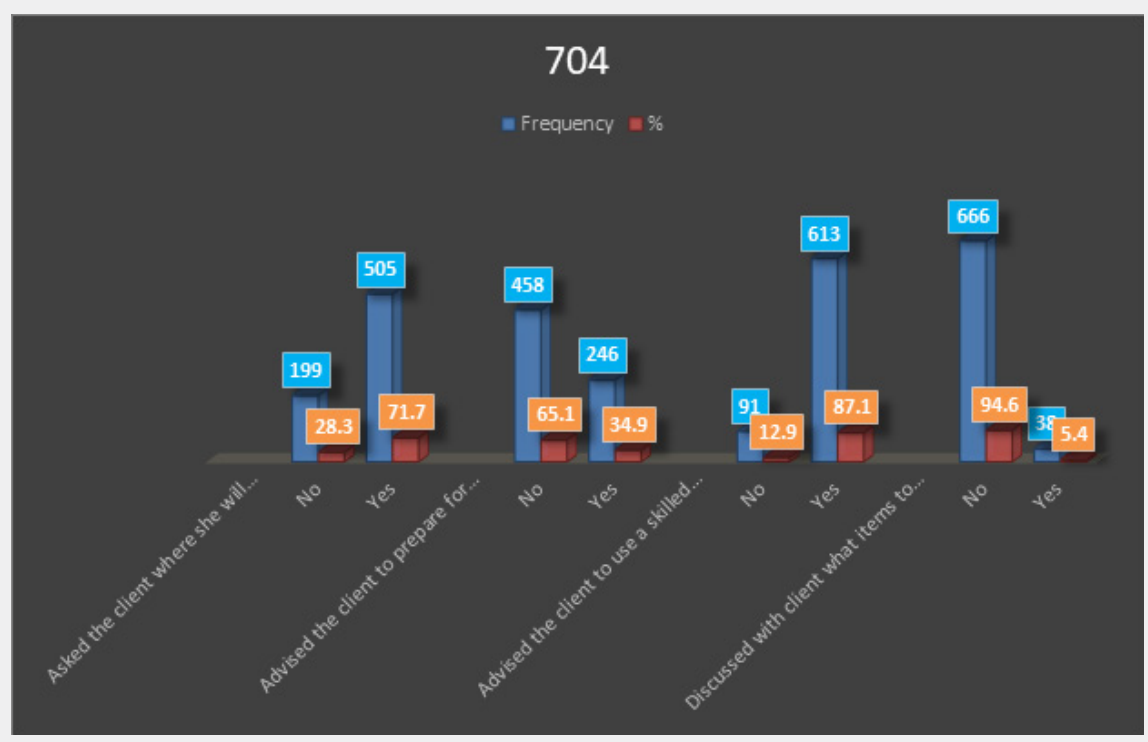

Figure 5: Service provider-client interaction process on preparation for delivery among Antenatal care service user in Public Hospitals of Woliata Zone, Southern Ethiopia Nov-Feb 2019.

Table 1: Service provider interaction process on antennal care service on client history, aspects of prior pregnancies and danger sign of current pregnancy among Antenatal care service user at Public hospitals of Woliata Zone, Southern Ethiopia Nov-Feb 2019.

\begin{tabular}{|c|c|c|}
\hline Description of Variables & N=704 & Frequency \\
\hline Client History & & \\
\hline Asked client or client mentioned the age & 609 & 86.5 \\
\hline Yes & & \\
\hline Asked medication taken & 330 & 46.9 \\
\hline Yes & & \\
\hline Asked date of last menstrual period & 630 \\
\hline Yes & & 89.5 \\
\hline Number of prior pregnancies client has had & 631 & \\
\hline Yes & & 89.6 \\
\hline
\end{tabular}




\section{Journal of Gynecology and Women's Health}

\begin{tabular}{|c|c|c|}
\hline Discussed aspects of $\mathrm{p}$ & & \\
\hline \multicolumn{3}{|c|}{ Prior stillbirth(s) } \\
\hline Yes & 579 & 82.2 \\
\hline \multicolumn{3}{|c|}{ Infant(s) who died in the first week of life } \\
\hline Yes & 561 & 79.7 \\
\hline \multicolumn{3}{|c|}{ Heavy bleeding, during or after delivery } \\
\hline Yes & 396 & 56.2 \\
\hline \multicolumn{3}{|c|}{ Previous assisted delivery (caesarean section, venous, or forceps) } \\
\hline Yes & 322 & 45.7 \\
\hline \multicolumn{3}{|c|}{ Previous spontaneous abortions } \\
\hline Yes & 603 & 85.7 \\
\hline \multicolumn{3}{|c|}{ Previous multiple pregnancies } \\
\hline Yes & 539 & 73.6 \\
\hline \multicolumn{3}{|c|}{ Previous prolonged labor } \\
\hline Yes & 102 & 14.5 \\
\hline \multicolumn{3}{|c|}{ Previous pregnancy-induced hypertension } \\
\hline Yes & 362 & 51.4 \\
\hline \multicolumn{3}{|c|}{ Previous pregnancy related convulsions } \\
\hline Yes & 319 & 45.3 \\
\hline \multicolumn{3}{|c|}{ High fever or infection during prior pregnancy/pregnancies } \\
\hline Yes & 379 & 53.8 \\
\hline \multicolumn{3}{|c|}{ Asked or client mentioned danger sign of current pregnancy } \\
\hline \multicolumn{3}{|c|}{ Vaginal bleeding } \\
\hline Yes & 467 & 66.3 \\
\hline \multicolumn{3}{|c|}{ Fever } \\
\hline Yes & 595 & 84.5 \\
\hline \multicolumn{3}{|c|}{ Headache or blurred vision } \\
\hline Yes & 661 & 93.9 \\
\hline \multicolumn{3}{|c|}{ Swollen face or hands } \\
\hline Yes & 491 & 69.7 \\
\hline \multicolumn{3}{|c|}{ Tiredness or breathlessness } \\
\hline Yes & 432 & 61.4 \\
\hline \multicolumn{3}{|c|}{ Foetal movement (loss of, excessive, normal) } \\
\hline Yes & 627 & 89.1 \\
\hline \multicolumn{3}{|c|}{ Cough or difficulty breathing for 3 weeks or longer } \\
\hline Yes & 682 & 6 \\
\hline \multicolumn{3}{|c|}{ Any other symptoms the client thinks might be related to this pregnancy } \\
\hline Yes & 373 & 53 \\
\hline
\end{tabular}

Table 2: Service provider-client interaction process on performing physical examination, and asking about recommended routine tests among Antenatal care service user in Public hospitals of Woliata Zone, Southern Ethiopia Nov-Feb 2019.

\begin{tabular}{|c|c|c|}
\hline The Provider Performed Physical Examination & N=704 & \\
\hline Take the client's blood pressure & & \\
\hline Yes & 616 & 87.5 \\
\hline Weigh the client & & \\
\hline
\end{tabular}




\section{Journal of Gynecology and Women's Health}

\begin{tabular}{|c|c|c|}
\hline Yes & 700 & 99.4 \\
\hline \multicolumn{3}{|c|}{ Examine conjunctiva/palms for anemia } \\
\hline Yes & 595 & 84.5 \\
\hline \multicolumn{3}{|c|}{ Examine legs/feet/hands for oedema } \\
\hline Yes & 399 & 56.7 \\
\hline \multicolumn{3}{|c|}{ Examine for swollen glands } \\
\hline Yes & 33 & 4.7 \\
\hline \multicolumn{3}{|c|}{ Palpate the client's abdomen for foetal presentation } \\
\hline Yes & 701 & 99.6 \\
\hline \multicolumn{3}{|c|}{ Palpate the client's abdomen for uterine height } \\
\hline Yes & 697 & 99 \\
\hline \multicolumn{3}{|c|}{ Listen to the client's abdomen for foetal heartbeat } \\
\hline Yes & 702 & 99.7 \\
\hline \multicolumn{3}{|c|}{ Conduct an ultrasound/refer client for ultrasound/look at recent ultrasound report } \\
\hline Yes & 326 & 46.3 \\
\hline \multicolumn{3}{|c|}{ Examine the client's breasts } \\
\hline Yes & 35 & 5 \\
\hline \multicolumn{3}{|c|}{ Conduct vaginal examination/exam of perinea area } \\
\hline Yes & 346 & 49.1 \\
\hline \multicolumn{3}{|c|}{ Measure fundal height using tape measure } \\
\hline Yes & 692 & 98.3 \\
\hline \multicolumn{3}{|c|}{ Asked anemia test } \\
\hline Yes & 581 & 82.5 \\
\hline \multicolumn{3}{|c|}{ Asked blood grouping } \\
\hline Yes & 573 & 81.4 \\
\hline \multicolumn{3}{|c|}{ Asked any urine test } \\
\hline Yes & 587 & 83.4 \\
\hline \multicolumn{3}{|c|}{ Asked syphilis test } \\
\hline Yes & 582 & 82.7 \\
\hline
\end{tabular}

Table 3: Service provider-client interaction process on performing recommended tests, and referring client for recommended routine tests, HIV testing, counselling and Maintaining healthy pregnancy among Antenatal care service user in Public Hospitals of Woliata Zone, Southern Ethiopia in 2019.

\begin{tabular}{|c|c|c|}
\hline Provider Performed Routine Tests & $\mathrm{N}=704$ & $\%$ \\
\hline \multicolumn{3}{|l|}{ Anaemia test } \\
\hline Yes & 568 & 80.7 \\
\hline \multicolumn{3}{|l|}{ Blood grouping } \\
\hline Yes & 560 & 79.5 \\
\hline \multicolumn{3}{|l|}{ Any urine test } \\
\hline Yes & 569 & 80.8 \\
\hline \multicolumn{3}{|l|}{ Syphilis test } \\
\hline Yes & 567 & 80.5 \\
\hline \multicolumn{3}{|l|}{ Provider referred the client } \\
\hline \multicolumn{3}{|l|}{ Anaemia test } \\
\hline Yes & 104 & 14.8 \\
\hline Blood grouping & & \\
\hline
\end{tabular}




\section{Journal of Gynecology and Women's Health}

\begin{tabular}{|c|c|c|}
\hline Yes & 114 & 16.2 \\
\hline \multicolumn{3}{|c|}{ Any urine test } \\
\hline Yes & 113 & 16.1 \\
\hline \multicolumn{3}{|c|}{ Syphilis test } \\
\hline Yes & 116 & 16.5 \\
\hline \multicolumn{3}{|c|}{ HIV counselling and testing } \\
\hline \multicolumn{3}{|c|}{ Asked if the client knew her HIV status } \\
\hline Yes & 520 & 73.9 \\
\hline \multicolumn{3}{|c|}{ Provide counselling related to HIV test } \\
\hline Yes & 518 & 73.6 \\
\hline \multicolumn{3}{|c|}{ Refer for counselling related to HIV test } \\
\hline Yes & 138 & 19.6 \\
\hline \multicolumn{3}{|c|}{ Perform HIV test } \\
\hline Yes & 550 & 78.1 \\
\hline \multicolumn{3}{|c|}{ Refer for HIV test } \\
\hline Yes & 30 & 4.3 \\
\hline \multicolumn{3}{|c|}{ Maintaining healthy pregnancy } \\
\hline \multicolumn{3}{|c|}{ Discussed nutrition (i.e. quantity or quality of food to eat) during the pregnancy } \\
\hline Yes & 579 & 82.2 \\
\hline \multicolumn{3}{|c|}{ Informed the client about the progress of the pregnancy } \\
\hline Yes & 596 & 84.7 \\
\hline \multicolumn{3}{|c|}{ Discussed the importance of at least 4 ANC visits } \\
\hline Yes & 530 & 75.3 \\
\hline
\end{tabular}

Table 4: Service provider-client interaction process on prescribing or giving iron pills or folic acid, tetanus toxoid injection, deworming, malaria prophylaxis among Antenatal care service user in Public Hospitals of Woliata Zone, Southern Ethiopia in 2019.

\begin{tabular}{|c|c|c|}
\hline Iron Prophylaxis & Frequency $\mathrm{N}=704$ & $\%$ \\
\hline \multicolumn{3}{|l|}{ Prescribed or gave iron pills or folic acid (IFA) or both } \\
\hline Yes & 593 & 84.2 \\
\hline \multicolumn{3}{|l|}{ Explained the purpose of iron or folic acid } \\
\hline Yes & 594 & 84.4 \\
\hline \multicolumn{3}{|l|}{ Explained how to take iron or folic-acid pills } \\
\hline Yes & 591 & 83.9 \\
\hline \multicolumn{3}{|l|}{ Explained side effects of iron pills } \\
\hline Yes & 571 & 81.1 \\
\hline \multicolumn{3}{|l|}{ tetanus toxoid injection } \\
\hline \multicolumn{3}{|l|}{ Prescribed or gave a tetanus toxoid (TT) injection } \\
\hline Yes & 568 & 80.7 \\
\hline \multicolumn{3}{|l|}{ Explained the purpose of the TT injection } \\
\hline Yes & 507 & 72 \\
\hline \multicolumn{3}{|l|}{ deworming } \\
\hline \multicolumn{3}{|l|}{ Prescribed or gave Mebendazole/Albendazole } \\
\hline Yes & 3 & 0.4 \\
\hline Explained the purpose of Mebendazole/Albendazole & & \\
\hline
\end{tabular}




\section{Journal of Gynecology and Women's Health}

\begin{tabular}{|c|c|c|}
\hline Yes & 2 & 0.3 \\
\hline \multicolumn{3}{|c|}{ malaria } \\
\hline \multicolumn{3}{|c|}{ Gave malaria prophylaxis medicine (SP) to client during the consultation } \\
\hline Yes & 2 & 0.3 \\
\hline \multicolumn{3}{|c|}{ Prescribed malaria prophylaxis medicine (SP) to client to obtain elsewhere } \\
\hline Yes & 3 & 0.4 \\
\hline \multicolumn{3}{|c|}{ Explained the purpose of the preventive treatment with anti-malaria medicine } \\
\hline Yes & 4 & 0.6 \\
\hline \multicolumn{3}{|c|}{ Explained how to take the anti-malaria medicine } \\
\hline Yes & 4 & 0.6 \\
\hline \multicolumn{3}{|c|}{ Explained possible side effects of the anti-malaria medicine } \\
\hline Yes & 3 & 0.4 \\
\hline \multicolumn{3}{|c|}{ Provided ITN to client as part of consultation or instructed client to obtain ITN elsewhere in facility } \\
\hline Yes & 94 & 13.4 \\
\hline \multicolumn{3}{|c|}{ Explicitly explained importance of using ITN to client } \\
\hline Yes & 127 & 18 \\
\hline
\end{tabular}

Table 5: Predictors of Process Quality of Antenatal Care among ANC attending pregnant women at four public health Hospitals in Woliata Zone, Southern 'Ethiopia, Nov- Feb, 2019.

\begin{tabular}{|c|c|c|c|c|}
\hline \multirow{2}{*}{ Predictor Variables } & \multirow[b]{2}{*}{ Unmet(<Median) } & \multirow[b]{2}{*}{ Met(>=Median) } & \multirow[t]{2}{*}{ Cor $(95 \%, \mathrm{Ci})$} & \multirow[t]{2}{*}{ Aor $(95 \%$, Ci) P.Value } \\
\hline & & & & \\
\hline $\begin{array}{l}\text { Advise the client to use skilled health } \\
\text { worker for delivery }\end{array}$ & $333(99.1)$ & $3(0.9)$ & 1 & \\
\hline \multicolumn{5}{|l|}{ No } \\
\hline Yes & $280(76.1)$ & $88(23.9)$ & $34.8(10.9,111.4)$ & $21.0(6.3,69.6) * 0.000$ \\
\hline $\begin{array}{l}\text { Discussed on heavy vaginal bleeding } \\
\text { during or after birth }\end{array}$ & $203(60.4)$ & $133(39.6)$ & 1 & \\
\hline \multicolumn{5}{|l|}{ No } \\
\hline Yes & 193(52.4) & $175(47.6)$ & $1.3(1.0,1,8)$ & $1.6(1.0,2.5) * 0.049$ \\
\hline Advise the client to prepare for delivery & $154(45.8)$ & $182(54.2)$ & 1 & \\
\hline \multicolumn{5}{|l|}{ No } \\
\hline Yes & $92(25.0)$ & $276(75.0)$ & $2.5(1.8,3.4)$ & $3.1(2.0,4.9) * 0.000$ \\
\hline Provide counselling related to HIV & $274(81.5)$ & 62(18.5.) & & \\
\hline \multicolumn{5}{|l|}{ No } \\
\hline Yes & $244(66.3)$ & $124(33.7)$ & $2.2(1.5,3.2)$ & $1.8(1.0,3.0) * 0.028$ \\
\hline Asked the client where she will deliver & $290(86.3)$ & $46(13.6)$ & 1 & \\
\hline \multicolumn{5}{|l|}{ No } \\
\hline Yes & $215(58.4)$ & $153(41.5)$ & $4.4(3.0,6.5)$ & $2.6(1.7,4.2) * 0.000$ \\
\hline Examine conjunctiva/palms for anaemia & $308(91.6)$ & $28(8.3)$ & & \\
\hline No & & & 1 & \\
\hline Yes & $287(77.9)$ & $81(22.0)$ & $3.1(1.9,4.9)$ & $1.8(1.0,3.1) * 0.033$ \\
\hline \multicolumn{5}{|l|}{ Take client's blood pressure } \\
\hline \multirow[t]{2}{*}{ No } & $317(94.3)$ & 19(5.7) & & \\
\hline & & & 1 & \\
\hline Yes & $299(81.2)$ & $69(18.8)$ & $3.8(2.2,6.5)$ & $2.1(1.1,4.2) * 0.019$ \\
\hline
\end{tabular}




\begin{tabular}{|c|c|c|c|c|}
\hline Asked any urine test & $297(88.3)$ & $39(10.7)$ & & \\
\hline No & & & 1 & \\
\hline \multirow[t]{2}{*}{ Yes } & $290(78.8)$ & $78(21.1)$ & & \\
\hline & & & $0.4(0.3,0.7)$ & $3.7(0.7,17.6) 0.099$ \\
\hline Asked anaemia test & $295(87.7)$ & $41(12.2)$ & 1 & \\
\hline \multicolumn{5}{|l|}{ No } \\
\hline Yes & $286(77.7)$ & $82(22.2)$ & $2.0(1.3,3.1)$ & $3.0(0.6,13.3) 0.141$ \\
\hline Perform Blood grouping & $282(83.9)$ & $54(16.1)$ & 1 & \\
\hline \multicolumn{5}{|l|}{ No } \\
\hline Yes & $278(75.6)$ & $90(24.4)$ & $1.7(1.1,2.4)$ & $0.6(0.3,1.1) 0.119$ \\
\hline Asked client for foetal movement & 286 & 50 & & \\
\hline No & & & 1 & \\
\hline Yes & 276 & 92 & $1.9(1.1,3.1)$ & $1.2(0.6,2.3) 0.571$ \\
\hline
\end{tabular}

*Statistically significant at $\mathrm{p}$-value $<0.05,1$ stands for reference variables. AOR for raising a given predictor (xi) by 1 unit holding all other predictors constant. $\mathrm{COR} /(\mathrm{OR})$ is a measure of association between an exposure and an outcome.

\section{Model Description}

Variables which were significant at bivariate analysis with p-value less than 0.25 were included in the multiple variable logistic regressions. Assumption of logistic regression was checked by Hosmer-Lemeshow goodness of-fit-test, result 0.056 .

\section{Discussion}

The study estimated the proportion of process quality of Antenatal care services which has been conducted among Antenatal care service users and health care providers at four public hospitals of Woliata zone, Southern Ethiopia. The overall proportion of process quality of ANC) met in this study was $52.3 \%$. This is low as most pregnancies and births are uneventful, all pregnancies are at risk. Around 15\% of all pregnant women develop a potentially life-threatening complication that calls for skilled care and some will require a major obstetrical intervention to survive thus every ANC client need to be advised [22].

Meeting only $52.3 \%$ of process quality antenatal care services might be explained by lack of awareness of receivers on Focused Antenatal Care Services (FANC), the right to discuss her concerns, a right to information about her health, a right to express her views about the service she receives. experience of the provider and the service receiver, trained human resource for health care 'not undertaking the recommended intervention by health care provider, the absence of the experienced provider in due time and the expectation of mothers.

In this study process quality of ANC was predicted by advise the client to use skilled health worker for delivery, discussed vaginal bleeding during or after birth, taking clients blood pressure, advise the client to prepare for delivery, asked client where she will deliver, Provide counselling related to HIV and examine conjunctiva/palms for anaemia Mothers who received advice to use skilled health worker for delivery during their ANC visit accounts 613(87.1\%) which is higher than a study conducted in Rural Gambia in which $70 \%$ of women were advised to use skilled health worker [30]. A study conducted in southern Ethiopia lower that is $40.6 \%$ were advised to use SBA [31]. This difference might be due to sample size, data collection approach, study setting, and number of health facilities used.

Mothers who had got advice to use skilled health worker for delivery were twenty- one times more likely to have process quality of ANC than mothers who had not had. This might be justified by understanding the benefit of the skilled health worker, and previous experience. Obstetric care from a trained provider during delivery is recognized as critical for the reduction of maternal and neonatal mortality. Because births delivered at a health facility are more likely to be delivered by a trained health professional [32]. Thus, with no precondition advice to pregnant women should be given during ANC visit to attain the SDG2030 Goal. In addition to that different studies confirmed that the probability of giving birth at health care facilities could be affected by several factors including place of residence, mother's demographic and socioeconomic characteristics, and availability and quality of health services $[33,34]$.

Women who were informed/discussed about vaginal bleeding during or after birth is $66.3 \%$ which is low compared to ante partum haemorrhage when there is $>500 \mathrm{ml}$ blood loss (whereas bleeding in the first trimester is known as a threatened abortion), it will result in placental abruption and uterine rupture may be accompanied by severe pain and other indications [35]. The proportion is higher compared with women who were informed of this pregnancy complication in SNNPR [32] and still it is higher than a study conducted in governmental Health Facilities of Harar 
Town, Eastern Ethiopia [36]. This is difference in proportion might be due to the study setting, sample size, data collection approach and tools used.

The study also showed that mothers who had discussed vaginal bleeding with provider were one point six times more likely to get process quality of ANC than mothers who did not discuss. This might be explained by the awareness and experience of the clients regarding the risk of vaginal bleeding as a result of previous births, age as well the educational status and the follow up she has had. Mothers whose blood pressure measured in this study is $616(87.5 \%)$ which is low compared to several life-threatening complications that will result if not measured eclampsia is diagnosed with raised BP (> 140/90) AND proteinuria. It can worsen very rapidly. Pre-eclampsia is a leading cause of maternal death and stillbirth so regular ANC attendance are vital and the BP should always be measured [35] Whereas the proportion is higher compared to women who received ANC, about 4 in 5 women $(75 \%)$ in Ethiopia at national level [30,32]. And from a study conducted in Kenya in which $56.7 \%$ ANC attending women BP was measured [37]. Whereas it lowers in a s study conducted in Kinshasa, Democratic Republic of Congo [38]. This is difference in proportion might be due to the study setting, sample size, data collection approach here, the approach used was direct observation, and tools used in this study were standardized checklist.

Mothers whose blood pressure measured more than two times more likely to have had process quality of ANC than those whose blood pressure were not measured. A study conducted in Malawi indicated that odds of blood pressure measured were three times greater than this study [39]. This might be justified by the awareness they have about the risk of not measured blood pressure whenever they visit the public health facility, experience they have had from previous births, accumulated Knowledge from different sources for instance media, health facilities etc. The proportion of mothers who were advised to prepare for delivery were $246(34.9 \%)$. This is very low as compared to a standard set by world health organization which states all pregnant women should have a written plan for birth and dealing with unexpected adverse events, such as complications or emergencies that may occur during pregnancies, child birth or immediate postnatal period, and should discuss review this plan with a skilled attendant at each antenatal assessment and at least one month prior to the expected date of delivery [40]. Maternal under nutrition and irondeficiency anaemia increase the risk of maternal death, accounting for at least $20 \%$ of maternal mortality [41].

Emergency transportation is another issue in getting prepared for delivery \& its benefit is highly related with saving the life of the mother and her foetus. If not prepared for this everybody can imagine the impact as mentioned in a study. This difference might be explained by, experience they have during follow up ANC, feeling the risk if missed or understanding the benefit of examining. Those mothers who were advised to prepare for delivery were more than three times more likely to have process quality of ANC than those who were not. Thus, advising ANC clients to get prepared for delivery is a paramount importance.

The proportion of mothers who received counselling related to HIV tests were $518(73.6 \%)$. This is low compared to the principles and routine screening standards of Centre for communicable Disease Control (CDC) which states, Health care providers should provide HIV counselling and offer testing to women before they become pregnant or as early in pregnancy as possible to allow women to know their infection status both for their own health and to reduce the risk for prenatal HIV transmission. Informed and timely therapeutic and reproductive decisions can then be made by the woman if she is HIV positive [42]. The most effective interventions to reduce transmission from mother to child depend upon a woman knowing her HIV status, and that, in turn, depends upon the availability of information, counselling and voluntary testing services [43]. The results revealed that the clients have process quality of ANC more and more if and only the health personals are in line with national health service care standards as well to meet the need of Antenatal clients there by provide process quality service so as to meet SDG2030.

Those mothers who were provided counselling related to HIV almost two times more likely to have process quality of ANC than those who were not. This difference might be explained by the effect of counselling on the issue, the awareness regarding the benefit. The proportion of mothers who were asked their plan of delivery place 505(71.7\%).Most incidents of maternal deaths are due to direct obstetric causes such as haemorrhage, sepsis, unsafe abortion, obstructed labour, and hypertensive disorders as well as economy and short duration/uncomplicated labour were the predominant reason given by $86.74 \%$ of the women who had home delivery of their last child $[44,45]$ to avert this problem and to meet the process quality of antenatal care services the providers should ask the place of delivery of pregnant women; and give advice in this regard.

Those mothers who were asked where she will deliver were almost three times more likely to get process quality of antenatal care compared to those who did not. This might be explained by the awareness and experience of the clients regarding the getting informed asked and informed about place of delivery because of educational status and the follow up she has had.

The proportion of mothers who were examined for conjunctivitis or palms for anaemia accounts 595(84.5\%). Although diagnosis of anaemia can easily be done by traditional Sahil's haemoglobin meter, or more recently by electronic cell counters, yet physicians and healthcare workers try to detect anaemia by looking at conjunctiva, tongue, palmer, or nail bed pallor thus this must be undertaken. Women of reproductive age and small children are at greatest risk, with an estimated 50\% 
to $60 \%$ of pregnant women and $40 \%$ of small children suffering from anaemia, Anaemia during pregnancy is a major health concern because it has been associated with increased risks of maternal morbidity [46-49]. This is low compared to Women of reproductive age and small children are at greatest risk, with an estimated $50 \%$ to $60 \%$ of pregnant women and $40 \%$ of small children suffering from anaemia, Anaemia during pregnancy is a major health concern because it has been associated with increased risks of maternal morbidity.

Those mothers who were examined for conjunctivitis or palms for anaemia were almost two times likely to get process quality of antenatal care than compared to those who had not had the examination. This might be explained by the awareness and experience of the clients regarding the risk of anaemia because of previous births, age as well the educational status and the follow up she has had. The Process quality situation in the Woliata Zone is far from the national standards by Federal Ministry of Health of Ethiopia where it set quality of maternal health service care to be 85\%(9).Thus, to get overall quality maternal health service care, it is a must to be in line with process quality of the service.

\section{Conclusion}

This study revealed that process quality of ANC is low as compared to national standard for maternal health care quality. The statistically significant variables which affected process quality of antenatal care service independently are advise the client to use skilled health worker for delivery, discussed vaginal bleeding, take client's blood pressure, examine legs/ feet/ hands / for oedema, advise the client to prepare for delivery, provide counselling related to HIV.

\section{Recommendation}

\section{Health Care provider}

a) It is good of all health care providers to give advice on a skilled birth attendance for ANC clients in line with national and world health organization standards.

b) It is better for even ANC clients to interact with health care provider in detail on what to prepare.

c) It is good of all health care provider to ask again and again the clients till she mentions what are stated in national guideline as well the client need to mention vaginal bleeding related issues, bearing the consequences of vaginal bleeding

d) It would be of good if the health care providers take whenever the ANC clients visit and advise her if she can selfmonitor her plod pressure, and the client mention the provider that she /he had not measured Blood pressure.

e) It would be of good if all healthcare providers advise the client to prepare for delivery, provide counselling related to HIV by taking account its bad health effect. f) In order to reduce morbidity and mortality of delivering women, it would be good if health care providers identify the clients' preference place of delivery to act according to their preference.

g) Since anaemia is one of the leading causes for morbidity and mortality of pregnant women thus attention should be given in examining conjunctivitis, palms for anaemia

\section{Woliata Zone Health care administrative and Southern Region health Bureau}

a) They should give refreshment training on process quality of Antenatal care for health care providers.

b) The region should give training to Zone health office on the importance of process quality of ANC to meet SDG2030

c) It would be of good if Strengthen health care system via integrated supportive supervision and using some technologies which will positively affect process quality of ANC.

d) It would be good of them to see the competencies of their health care provider intermes of process quality of ANC.

e) It would be good of them to assign more experienced health care providers with those who have less experience there by enable others to learn more how process quality of ANC be maintained.

\section{Federal Ministry of Health, Ethiopia}

a) Better try to be in line with World health Organization and National Quality of health Care service delivery there by address process quality of ANC.

b) -Better to let ministry health managers to have experience sharing of process quality maternal health care service in general and ANC. And let them share this experience to all Zone health care mangers.

\section{Strength and Limitation of the study}

The study has utilized direct observation methods of data collection to measure process Quality of antenatal care services and valid sources of tools. This could increase the validity of the tool and the internal and external validity of the study. The probable limitation is hawthorn effect: It was the presence of an observer during the client-provider interaction, which might have improved provider performance, as well as reduced client openness, in response to the fact that they are being observed which was tired to reduce using ODK app as data collection platform and explaining the objectives of the study in detail.

\section{Conflict of Interests}

All authors declare that they have no conflict of interests. The sponsor of the study had no role in study design; in the collection, analysis, and interpretation of data; in the writing of this report; in 
the decision to submit the paper for publication.

\section{Ethics approval and consent to participate}

The study was approved by the University College Dublin Human Research Ethics Committee School of Public Health and Sport Sciences and Institutional Review Board of Woliata Sodo University to conduct the study in four hospitals of Woliata Zone. In addition, Woliata Zone health Office provided support letter to access selected hospitals. Written consent was obtained from each study participant. Data were de-identified to maintain confidentiality.

\section{Funding}

This project has received funding from the European Union's Horizon 2020 research and innovation programme under the Marie Skłodowska-Curie grant agreement No 778196. This study was made possible by the support of UCD and WSU. The contents are the responsibility of WSU and do not necessarily reflect the views of UCD. UCD did not have any additional role in the study design, data collection and analysis, interpretation of the data, or preparation of the manuscript. Study participants did not receive financial incentives for their participation in the study.

\section{Availability of Data and Materials}

The datasets used and/or analysed during the current study are available from the corresponding author on reasonable request.

\section{Authors' Contributions}

a) NM contributed to the study design, managing data collection, performed the data analysis, interpretation of data and wrote the manuscript.

b) $\mathrm{MC}, \mathrm{TT}, \mathrm{AD}, \mathrm{FM}$ and $\mathrm{CP}$ contributed to interpretation of data, the development of the study

c) design and reviewing the manuscript. All authors read and agreed to be accountable for the whole process of the manuscript development; and they approved the final manuscript.

\section{References}

1. AbouZahr C (2014) Women's Health Meeting: Trends and Projections for Mortality and Morbidity. pp. 1-35.

2. Tolefac PN H-EG, Agbor VN, Sama CB, Ngwasiri C, Tebeu PM, et al. (2017) Maternal Health Neonatol Perinatol. Why do pregnant women present late for their first antenatal care consultation in Cameroon?

3. Tadese Ejigu MWaYK (2013) Quality of antenatal care services at public health facilities of Bahir-Dar special zone, Northwest Ethiopia. BMC Health Services Research 13(443).

4. AbouZahr C (2013) Women's Health Meeting: Trends and Projections for Mortality and Morbidity.

5. Mesfin Markos AA (2020) Kebreab Paulos Partograph Utilization and
Associated Factors among Obstetric Care Providers Working in Public Health Facilities of Wolaita Zone, 2017. Hindawi Journal of Pregnancy, p. 8.

6. Komuhangi G (2020) Socio-Demographics and late antenatal care seeking behavior: a cross sectional study among pregnant women at kyenjojo general hospital, western Uganda. Open Journal of Nursing 10(1): 69-86.

7. WHO (2015) World health statistics.

8. Ayalew F, Eyassu G, Seyoum N, Roosmalen JV, Bazant E, et al. (2017) Using a quality improvement model to enhance providers' performance in maternal and newborn health care: a post-only intervention and comparison design. BMC Pregnancy and Childbirth 17(1): 115.

9. FDREMOH (2015) Health Sector Development Program IV 2010/11 $-2014 / 15$.

10. Erchafo BAT, Tsega G, Adamu A, Yitbarek K, Siraneh Y, et al. (2018) Are we too far from being client centered? Plos One 13(10): e0205681.

11. Birhanu Z (2010) Determinants of satisfaction with health care provider interactions at health centers in central Ethiopia: a cross sectional study. BMC Health Serv Res 10: 78.

12. Geyndt WD (1995) Managing the quality of health care in developing countries world bank technical papers.

13. Teklehaimanot YK, Yohannes AG, Girma S, Seyoum S, Desta S, et al. (2007) Study of the Working Conditions of Health Extension Workers in Ethiopia. African Journal OnLine (AJOL) 21(3).

14. Donabedian's A (1982) Explorations in quality assessment and monitoring. The criteria and standards of quality. Ann Arbor, Mich: Health Administration Press. Ann Arbor, Mich Health Administration Press

15. Avedis D (1988) The quality of care: How can it be assessed? JAMA 260(12): 1743-1748.

16. Boyer CA (2010) Examining critical health policy issues within and beyond the clinical encounter: patient-provider relationships and help-seeking behaviors. J Health Soc Behav 51( Suppl 1) :S80-S93.

17. Annabelle G, Wringe A, Birdthistle I, Mshana G, Michael D, et al. (2014) It is like that, we didn't understand each other": exploring the influence of patient-provider interactions on prevention of mother-tochild transmission of HIV service use in rural Tanzania. PLoS One 9(9): e106325.

18. Kleinbaum DG, Kupper LL, Nizam A, Muller KE (2007) Applied regression analysis and other multivariable methods. Duxbury Press, USA.

19. Heritage J (2006) Problems and prospects in the study of physicianpatient interaction: 30 years of research. Annu Rev Social 32: 351-374.

20. McWhinney IR (1989) A Textbook of Family Medicine. The University of Michigan: Oxford University Press, USA, p. 380.

21. WHO (2016) WHO recommendations on antenatal care for a positive pregnancy experience. World Health Organization.

22. WHO (2002) Antenatal care randomized trial: manual for the implementation of the new model. World Health Organization.

23. Bahailu Balcha DE, Tilahun Beyene (2019) Client satisfaction with prevention of mother to child transmission of HIV services in public hospitals of hadiya zone, Southern Ethiopia. J Fam Med Dis Prev 5: 116.

24. Stuart L (2017) Transforming our world: The 2030 Agenda for Sustainable Development. 
25. WZHCAO (2016/17) Wolaita Zone Health Care Admistrative Office Report (2016/17).

26. Mulatu Melese DMBS, Muluken AA (2017) Low satisfaction of clients for the health Service provision in West Amhara region, Ethiopia. Plos one 12(6): e0179909.

27. Jeovany Martínez-Mesa DAG-C, Bastos JL, Bonamigo RR, Duquia RP (2014) Sample size: how many participants do I need in my research? brasileiros de dermatologic 89(4): 609-615.

28. FDREMOH (2016) Health sector transformation in quality: guide to support implementation of health service Quality Improvement activities in Ethiopian health facilities.

29. (2012) ESA: ICS Primary hospital requirements, in Human resource management \& service standards.

30. Macro CSAEaO (2016) Ethiopia Demographic and Health Survey Addis Ababa, Ethiopia, and Calverton, Maryland, Central Statistical Agency and ORC Macro, USA.

31. Gebre MGA, Abebe TA (2015) Birth preparedness and complication readiness among pregnant women in duguna fango district, wolayta zone, Ethiopia. Plos one 10(9): e0137570.

32. CSA (2016) Demographic and health survey addis ababa, Ethiopia, and calverton, maryland, central statistical agency and orc macro, USA.

33. Sugathan KS, Rather FRD (2011) Promoting institutional deliveries in rural India: The role of antenatal-care services, in national family health survey subject reports. Mumbai, India.

34. Daniel A (2018) Institutional delivery service utilization and its associated factors among women who gave birth during the past one year in mizan aman city administration, bench maji zone, South West Ethiopia. Ann Med Health Sci Res 8: 54-61.

35. WHO (2015) Treatment guidelines in line with essential package of health services. hospital and referral health centre guidelines. In: MOH (Ed.), UN agencies and THET, USA.

36. Tekelehaymanot G (2018) Assessment of quality of antenatal care service provision and associated factor at governmental health facilities of harar town, Eastern Ethiopia, 2017. J Multidis Res Rev 6: 367.

37. Cohen CR (2019) Quality of antenatal care and associated factors in a rural county in Kenya: an assessment of service provision and experience dimensions. BMC Health Services Research 19(1): 684.
38. Dalau Mukadi NJD, Wembodinga G, Bernard P, Antoinette T, Robert A, et al. (2019) Proportion of pregnant women screened for hypertensive disorders in pregnancy and its associated factors within antenatal clinics of Kinshasa, Democratic Republic of Congo BMC Pregnancy and Childbirth 19: 297.

39. William Stones (2018) Malawi: Findings from a national census of health facilities. Malawi Medical Journal 30(3):141-145.

40. WHO (2006) Standards for maternal and neonatal care the department making pregnancy safer.

41. WHO (2013) Meeting to develop a global consensus on preconception care to reduce maternal and childhood mortality and morbidity. World Health Organization, Geneva, Switzerland.

42. CDC (2006) CfcD Mother-to-Child (Perinatal) HIV Transmission and Prevention.

43. UNAIDS (2001) Counselling and voluntary HIV testing for pregnant women in high HIV prevalence countries, Joint United Nations Programme on HIV/AIDS

44. Ronsmans CGW (2006) Maternal mortality: who, when, where, and why. Lancet 368(9542): 1189-200.

45. Yegezu RT (2014) Assessment of Factors Affecting Choice of Delivery Place among Pregnant Women in Jimma Zone, South West Ethiopia: Cross Sectional Study. J Women's Health Care 4: 211.

46. ER (1982) The prevalence of nutritional anaemia in women in developing countries: a critical review of available information. World Health Stat Q 35: 52-59.

47. Sheth TN, Bowes M, Detsky AS (1997) The relation of conjunctival pallor to the presence of anemia. J Gen Intern Med 12(102): 106.

48. DeMaeyer EM A-TM (1985) The prevalence of anaemia in the world. World Health StatQ 38(302): 16.

49. Patterson JA, Gregory M, Holt S, Pachulski A, Stamford D, et al. (1994) A study on the effects of low haemoglobin on postnatal women. Midwifery 10(2): 77-86.

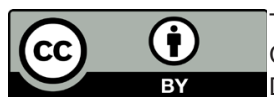

\section{Your next submission with Juniper Publishers will reach you the below assets}

- Quality Editorial service

- Swift Peer Review

- Reprints availability

- E-prints Service

- Manuscript Podcast for convenient understanding

- Global attainment for your research

- Manuscript accessibility in different formats

( Pdf, E-pub, Full Tsext, Audio)

- Unceasing customer service

Track the below URL for one-step submission

https://juniperpublishers.com/online-submission.php 